\title{
A novel 25 bp tandem repeat within the human trefoil peptide gene TFF2 in 21q22.3: polymorphism and mammalian evolution
}

\author{
Tuncay K ayademir ${ }^{1}$, Elisabeth dos Santos Silva ${ }^{1}$, Carsten Pusch ${ }^{1}$, Stefanie Beck ${ }^{1}$, \\ Jose-Carlos M achado ${ }^{1,2}$ and Peter $\mathrm{G}_{\text {ött }}{ }^{1}$ \\ ${ }^{1}$ D ivision of M olecular $G$ enetics, D epartment of A nthropology and $H$ uman $G$ enetics, U niversity of Tübingen, \\ Germany \\ ${ }^{2}$ Institute of M olecular Pathology and Immunology of University of Porto, M edical Faculty, Porto, Portugal
}

Trefoil peptides belong to a family of small secretory proteins characterised by three intrachain disulfide bonds forming the trefoil motif (TFF-domain). They serve to maintain or repair the epithelial mucosa, and promote cell migration. They are predominantly found in gastrointestinal tissues, and are upregulated around areas of epithelial damage, and in meta- and neoplasia. The corresponding three genes are clustered in human 21q22.3. TFF2 is the only human one encoding two TFF-domains on separate exons. In between (intron 2), a novel $\mathbf{2 5}$ bp sequence is located that is tandemly repeated approximately $\mathbf{4 8}$ times, but is unique in the human genome. A diallelic polymorphism with a second allele comprising approximately 53 repeat units is present among individuals. Both alleles were cloned on BAC recombinants. In Caucasians $(n=78)$ the allele frequencies found are 0.85 and 0.15 , respectively, representing a frequency of heterozygosity of $26 \%$. Ape and monkey species exhibit homologous repeats of shorter total array length, whereas none is found in other mammals.

Keywords: TFF-domain; trefoil factor family; bacterial artificial chromosomes; BAC; pS2/BCEl; hP1.B/hITF; hSP/SML1; TFF; spasmolytic protein; minisatellite

\section{Introduction}

In recent years a new cysteine-rich structural motif of about 50 amino acid residues, known as the trefoil or TFF-domain (trefoil factor family) has been

Correspondence: D r Peter G ött, U niversität T übingen, Institut für A nthropologie und $\mathrm{H}$ umangenetik, A bt. Molekulare G enetik, Wilhelmstr. 27, D-72074 Tübingen, Germany. Fax: (49) 7071-296409, Tel: (49) 7071-2976401,

E mail: peter.goett@uni-tuebingen.de

R eceived 23 June 1997; revised 150 ctober 1997; accepted 31 O ctober 1997 described. ${ }^{1,2}$ The conserved six cysteine residues form three intramolecular disulfide bridges resulting in three loops which are responsible for the trefoil-like shape and its resistance against proteolytic degradation. TFFdomains have been highly conserved during evolution; in $\mathrm{X}$ enopus, peptides as well as mucins contain multiple TFF-domains (for review, see ${ }^{3,4}$ ). In mammals, the three TFF members (new nomenclature, see ${ }^{5}$ ) are coordinately secreted in mucin expressing cells of the normal gastrointestinal tissues and are upregulated in pathological conditions such as damaged epithelia, sites 
of ulceration, and some meta- and neoplasia. TFF1, originally found in breast cancer cell lines (formerly termed pS2 or breast cancer oestrogen-inducible $B C E I$ ) is produced mainly in the foveolar part of the stomach, TFF 2 (formerly spasmolytic peptide, SP) is expressed in the glandular region of the stomach and duodenal Brunner's glands, while TFF 3 is expressed by the goblet cells of the intestine.

A lthough their precise physiological role is not understood, recent in vitro models propose that the peptides are involved in the maintenance of mucosal integrity and may accelerate wound healing by enhancing cell migration. ${ }^{6-8}$ Oral and subcutaneous application of trefoil peptides can protect against induced gastric injury in rats. ${ }^{9,10}$ TFF3 knockout mice are sensitive to dextran sulphate-induced colitis. ${ }^{11}$ TFF 1 knockout mice lost the expression of gastric mucus, developed gastric adenomas and, to a degree, invasive carcinomas, suggesting a tumor suppressor function. ${ }^{12}$ Interestingly, some $30 \%$ of these mice display a complete loss of TFF 2 transcription.

A t the gene level, we recently mapped the genomic locus of the human TFF 3 to $21 q 22.3^{13}$ in the region also assigned to TFF 1 and TFF $2,{ }^{14}$ and found the clustering of all three genes within a region of $50 \mathrm{~kb}$ by isolating a contig of genomic fragments cloned into the Bacterial A rtificial Chromosome (BAC) system. ${ }^{15,16}$ The unidirectional orientation of transcription and the closer localisation of the two stomach specific genes TFF 1 and TFF 2 is reflected by a coordinated cell- and tissuespecific gene expression. In stomach, pancreas and biliary tract carcinomas, the presence of the regular TFF 1 mRNA is strongly correlated with TFF 2 expression. ${ }^{17-19}$ This coexpression was also noted in ulceration-associated cell lineage in Crohn's disease. ${ }^{20}$ In hyperplastic gastric polyps, TFF 1 and TFF 3 are coexpressed, whereas in some gastric cancer and cell lines all three genes are active. ${ }^{16}$

A mong the three TFF genes, TFF2 is located centrally in the cluster and is the only one encoding two TFF-domains. The modular architecture of the genes is reflected by the fact that the TFF-domains are encoded by a single exon in TFF $1^{21}$ and TFF $3{ }^{22}$ whereas two adjacent exons encode the TFF-domains in TFF $2 .{ }^{16}$ This conserved structural organisation may have emerged from gene duplication and exon shuffling during evolution. It may be just a coincidence that the TFFencoding exons in TFF2 are separated by an intron containing a new tandem repeat cluster (minisatellite), the characteristics of which are described here. How- ever, it may turn out to be of functional relevance in modulating gene expression due to a binding site for a transcription factor, or interfering with gene expression, or causing genetic instability. R ecent examples related to these functions are the diabetes susceptibility locus IDDM 2, ${ }^{23}$ a minisatellite expansion in a noncoding part of a gene also found in 21q22.3 that is responsible for a monogenic form of epilepsy, ${ }^{24,25}$ or the fragile $X$ syndrome caused by minisatellite expansion in FRA 16B. ${ }^{26}$

\section{Materials and Methods}

\section{DNA Samples and Probes}

$G$ enomic D NA was isolated from various mammalian species by standard methods. Genomic DNA from healthy Caucasians was provided by $\mathrm{Dr} C \mathrm{~L}$ uckenbach, Tübingen. The great ape and monkey D NA ( $1 \mu \mathrm{g}$ each) were a kind gift from W Schempp, Freiburg. TFF positive recombinants were obtained $^{16}$ from the human genomic BAC library. ${ }^{27}$ BAC D NA was prepared by standard alkaline lysis and purified by phenol/chloroform and ethanol precipitation.

\section{Restriction Analysis, Southern Blotting and Hybridisation}

$\mathrm{H}$ indlII restriction digests of $B A C D N A$ were separated on $0.7 \%$ agarose-TAE gels. DNA was transferred in alkaline buffer for $2 \mathrm{~h}$ to Nytran membrane (Schleicher \& Schüll, $D$ assel, Germany) by downward blotting. ${ }^{28}$ For filter hybridisation, the probes were labelled with ${ }^{32} \mathrm{P}-\mathrm{dATP}$ by random priming (Boehringer $M$ annheim Biochemicals, $M$ annheim, Germany). A 300 bp cDNA fragment of TFF2 was isolated from pGEM-hsp200, ${ }^{2}$ kindly provided by $\mathrm{Dr} M-C \mathrm{R}$ io, Strasbourg. The ${ }^{32} \mathrm{P}$-labelled repeat-probe for hybridisation shown in Figure 4 was generated by PCR on template BAC 90 E 5 with oligonucleotides SMLF2 and SIN2 Table 1. The probe was hybridised at $65^{\circ} \mathrm{C}$ overnight in $7 \%$ SDS, $1 \mathrm{mM}$ EDTA , $500 \mathrm{mM}$ sodium phosphate buffer, $\mathrm{pH}=7.2$. $\mathrm{Mem}$ branes were washed twice at $65^{\circ} \mathrm{C}$ for $10 \mathrm{~min}$ in $0.1 \%$ SD S, $40 \mathrm{mM}$ sodium phosphate buffer, $\mathrm{pH}=7.2$, and exposed to autoradiography (Fuji RX, D üsseldorf, G ermany X -ray film) for 2 to 5 days.

\section{PCR Analysis}

Oligonucleotides were designed from CDNA or genomic sequences of TFF $2 .{ }^{2} \mathrm{PCR}$ primer sets flanking the repeats and listed in Table 1 were used for amplifications from $30 \mathrm{ng}$ BAC DNA or $100-250$ ng genomic DNA using Gold Star polymerase (Eurogentech, Belgium, Seraing, Belgium) or Expand Long Template PCR System (Boehringer Mannheim Biochemicals). PCR was processed according to different annealing temperatures using a synthesis time of $3 \mathrm{~min}$ (plus extension time of $20 \mathrm{~s}$ per cycle) and increased $\mathrm{M} \mathrm{g}$ concentration $(2.25 \mathrm{mM})$. Other conditions were applied as recommended by the manufacturers. For blunt end cloning assays Pwo-D NA -Polymerase (AGS, Heidelberg, Germany) was used under the same conditions as Taq-DNA-Polymerase except for the $2 \mathrm{mM} \mathrm{M} \mathrm{gSO}_{4}$ reaction buffer. 
Table 1 Primer pairs and PCR amplification products

\begin{tabular}{|c|c|c|c|c|c|}
\hline Name & $\begin{array}{l}\text { Localisation } \\
\text { in TFF2 }\end{array}$ & Sequence & $\begin{array}{l}\text { Template } \\
\text { (allele) }\end{array}$ & $\begin{array}{l}\text { PCR } \\
\text { product } \\
\text { (bp) }\end{array}$ & $\begin{array}{l}\text { A nnealing } \\
\text { temp. } \\
\text { degC }\end{array}$ \\
\hline $\begin{array}{l}\text { SMLF } \\
\text { SLM } \\
\text { SMLF } \\
\text { SINTR2 } \\
\text { SMLF2 } \\
\text { SIN2 } \\
\text { TFF2E 2F } \\
\text { TFF2E 3R }\end{array}$ & $\begin{array}{l}\text { Exon 2,f } \\
\text { Exon 3,r } \\
\text { Exon 2,f } \\
\text { Intron 2,r } \\
\text { Intron 2,f } \\
\text { Intron 2,r } \\
\text { Exon 2,f } \\
\text { Exon 3,r }\end{array}$ & $\begin{array}{l}\text { CACCA GTGACCAGTGTTTTGAC } \\
\text { GTTGGAGAAGCA CACTTCCG } \\
\text { CACCAGTGACCAGTGTTTTGAC } \\
\text { GAGGGCTGTCAGCCCTTATG } \\
\text { GAATCTTCCTGGGCCAGCA C } \\
\text { TTCATCTCACTGTTGGCTGACC } \\
\text { GTCCCYTGGTGTTTCCACCC } \\
\text { CTGATGCCCGGGTA SCCAC }\end{array}$ & $\begin{array}{l}\text { 90E } 5(A) \\
921 F 2(a) \\
90 E 5(A) \\
921 F 2(a) \\
90 E 5(A) \\
921 F 2(a) \\
90 E 5(A) \\
921 F 2(a)\end{array}$ & $\begin{array}{l}2400 \\
2500 \\
1600 \\
1700 \\
1400 \\
1500 \\
2600 \\
2700\end{array}$ & $\begin{array}{l}61 \\
61 \\
59 \\
59 \\
61 \\
61 \\
57 \\
57\end{array}$ \\
\hline
\end{tabular}

$f=$ forward; $r=$ reverse in respect of transcriptional direction.

Ligations, Sequence Analysis

TA -cloning of Taq PCR fragments with a pT 7 Blue Vector ( $N$ ovagen, M adison WI, USA) and blunt end cloning in pU C 18 (Pharmacia, Freiburg, G ermany) was performed using T4 D NA ligase under standard cloning conditions.

Cycle sequencing with ThermoSequenase (A mersham $L$ ife Science, Cleveland, $\mathrm{OH}, \mathrm{USA}$ ) using either ${ }^{32} \mathrm{P}$-primer labelling or ${ }^{35} \mathrm{~S}-\mathrm{dATP}$ internal labelling was performed according to the manufacturer's protocol. Primers used for sequencing were SMLF2, SIN2, SINTR2 and SIN25-71 (A A CCA A CCTAACCAACCTGGGCTAC) located in the $3^{\prime}$-end of the repeat. The sequence alignment and evaluation of the degree of homology was performed using $\mathrm{G}$ enB ank or E M B L databases on the databases of the $G$ enius Workstation of DKFZ, Heidelberg. Sequence data were processed by BLA ST N and SIM ILAR ITY algorithms of the G CG Wisconsin package. E M B L database accession numbers of intron 2 of TFF 2 are $X 97791$ and $X 97792$.

\section{Results \\ Identification and Amplification of the Repeat}

D uring cloning and sequencing the exon-intron boundaries of TFF $2,{ }^{16}$ we discovered a repetitive element in the intron 2 (Figure 1). A mong several overlapping BAC recombinants, BAC 921F 2 was chosen to determine a $\mathrm{H}$ indlII restriction map and use it as a template to amplify intron 2 by primers SM LF and SML (Figure 1 and Table 1). A $2.5 \mathrm{~kb}$ PCR product was obtained that was analysed by cycle sequencing, indicating a tandemly repeated motif in the $5^{\prime}$ half of intron 2 . TA -cloning of the $2.5 \mathrm{~kb}$ PCR fragment into a high copy number plasmid gave rise to various deletion inserts in

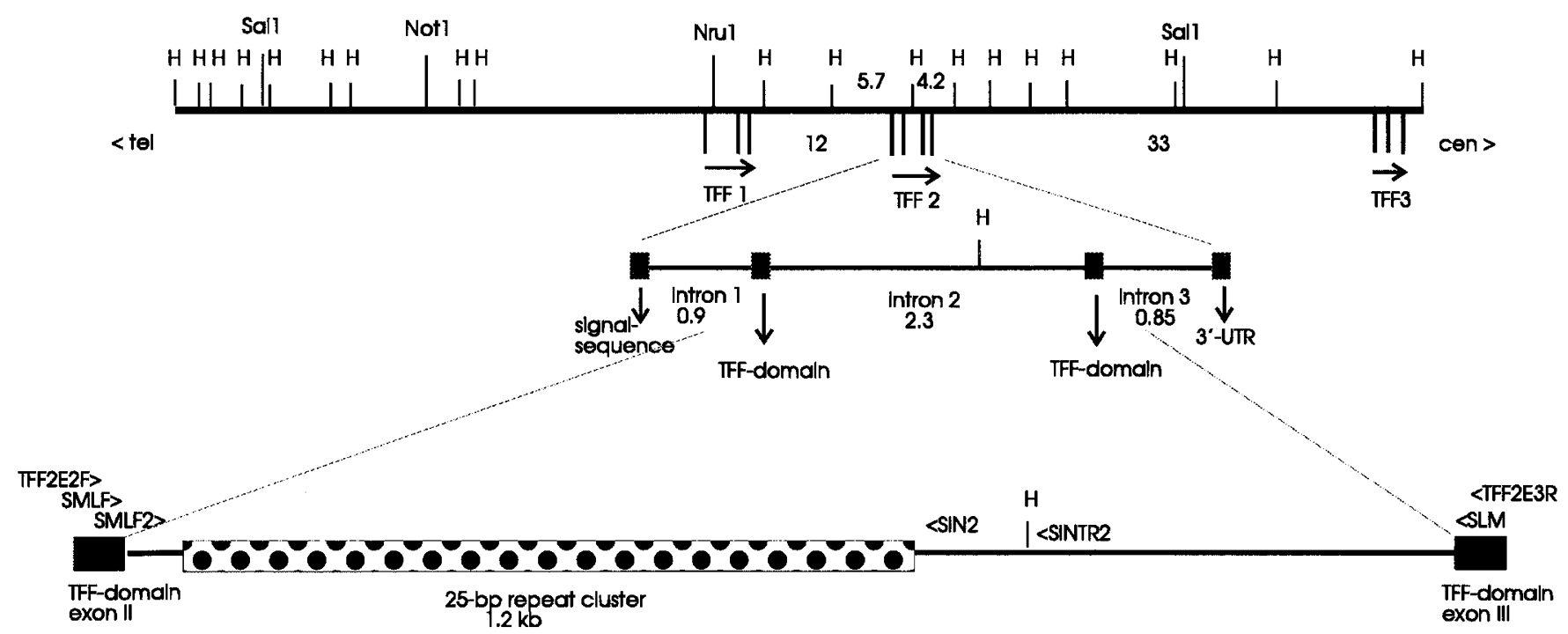

Figure 1 G enomic organization of the human TFF gene cluster in 21q22.3TFF 2 and the $25 \mathrm{bp}$ tandem repeats. B ars and black boxes refer to TFF exons. Top: $\mathrm{H}$ indIII (H) restriction map of BAC 921F 2 recombinant. B ottom: $M$ ap of the 25 bp repeat cluster in the intron 2 of TFF 2 and orientation of flanking primers. Numbers refer to distances in kilobases. 
the recombinant plasmids (data not shown). M oreover, attempts to subclone the corresponding $\mathrm{H}$ indl II restriction fragment of $5.7 \mathrm{~kb}$ known to contain intron 2 from BA C 921F 2 and BAC 90E 5 into pU C-derived vectors failed, although the adjacent restriction fragment of $4.2 \mathrm{~kb}$ as well as several other $\mathrm{H}$ indl I fragments of this size were successfully cloned. This indicates that the repeat is unclonable by standard cloning methods, as also observed for other tandem repeats. ${ }^{29}$ Cloning and sequencing of the adjacent $4.2 \mathrm{~kb} \mathrm{H}$ indlll restriction fragment allowed us to design new primers (SIN2, SINTR2, Table 1, Figure 1) for amplification of the entire tandem repeat cluster, and to determine the primary structure of intron 2 (EM B L database acc.no. $X 97791$ and $X$ 97792). The intron sequence downstream to the $\mathrm{H}$ indlII site matched perfectly the one published elsewhere, ( ${ }^{30}$ EMBL database accession no. U 47290 and U 47291).

\section{Primary Structure and Detection of Different Alleles}

Cycle sequencing from both ends of the amplified PCR products of 1.7 and $1.6 \mathrm{~kb}$ (Table 1 ) revealed a repetitive consensus sequence of $25 \mathrm{bp}$. Ten repeat units were determined on the $5^{\prime}$-end and eight repeat units on the 3 '-end (Figure 2). A t both sites at least twelve additional repetitive units were detected on autoradiographs, although their primary sequence was not

C $\quad \begin{array}{llllllll} & \mathrm{H} & \mathrm{P} & \mathrm{L} & \mathrm{P} & \mathrm{K} & \mathrm{Q}\end{array}$

TGTTTCCACCCCCTCCCAAAGCAAGGTAATCTTCCAGGGAATCTTCCTGG GCCAGCAGCTGGCAACCCAGGACCCAGCTTCACAGGCGGAGCCCAGAGCA GGGGCTGGAGGAGGCCCAGTTGCTAGTCTAGGGTTAGCCTGGGTGGGTTA GTCTCGAGCTAGCCCCGGTTGGTTAGTCTGGGGCTAGCCCAGGTTGGTTA GTCTAGAGCTAGCCCAGGTTGGTTAGTCTGGGGCTAGCCCAGGTTGGTTA GTCTGGGGCTAGCCCAGGTTGGTTAGTCTAGGGCTATCTAGGCTAGTTAG TCTAGAGCTACCCAGGTTGGTTAGTCTGGGGCTAGCCCAGGTTGGTTAGT CTGGGGCTAGCCCAGGTTGGTTAGTCT. . . . . . . . . .........590 bp (refer to allele A) ....... ...... TAGCCTTGGACTGNTAGTCTAGAGGTTAGCCTAGAGGACTGCT AGTCTAGAGGTAGTCTAGGGCTAGCCCAGGTTGGTTAGTCTGGGGTAGTC TGGGTAGCCNATGTTGGTTAGTNTTAGACTAGCCTGGA ${ }_{G}^{C}$ TGCTAGTCTAG AGGTAGCCCAGGTTGGTTAGTCTGGTACTAGCCTGGACTGTNAGTCTAGA GGTAGCCCAGGTTGGTTAGGTTGGTTAGTCTGGGACTAGTCTGGACTGTT AGTCTAGAGGTAGCCCAGGTTGGTTA GTTTGGGACTAGCCTGGACTGTTA GTCTAGAGGTAGCCCAGATTGGTTAGTCTGGGACTAGTCTGGACTGCTAG TCTAGAGGTAGCCCAGGTTGGTTAGCCTGGGGCCAGCCTGGACTGTTAGT CTAGAGGTAACCCAGGTCAGCCAACAGTGCAGATGAAAATTTCCCACCTA CCCTGTTTCTACACTGTTAGTTCTTTCAACAGACATGTGTGTGTGGAGCC ATCAGTTTTACTTTAGTTGAGAAAAAAATATATATATATATAGTAGGTCT CCTCTAGTTTTTGAAGTGTGACTTCTGAAGAAGCTTCCATGGGGAAATGA AGGTATTTAATAGGACAGCAGTAACATAAGGGCTGACAGCCCTCAAATGT

Figure 2 Flanking sequences of the 25 bp repeat cluster. E xon 2 and the $\mathrm{H}$ ind III restriction site - bold type; primers SM L F2, SIN2, SINTR 2 and SIN25-71 - underlined. (EMBL database acc.no.X 97791 and $X$ 97792); 25 bp consensus motif (AG TC $T_{G}^{A} G G G C T A G$ C CCAGGTTGGTT) -. The 590 bp sequence not determined by nucleotide sequencing refers to allele $A$. unambiguously determined, indicating a total array size of at least 40 repeat units. As determined from the length of the amplified PCR product $(1.7 \mathrm{~kb}$, SMLF2SIN2, on BAC 921F2, Table 1) the total array size was estimated to be $1.32 \mathrm{~kb}$ equalling a total copy number of 53 tandem repeats. PCR amplification from four additional BAC clones (43A 9, 90E 5, 548B 9, 843E 9, ${ }^{16}$ ) yielded total array sizes that are $120 \mathrm{bp}$ shorter than the corresponding one of clone 921F2. Sequence analysis of both ends of the repetitive cluster from template $90 \mathrm{E} 5$ exhibited no differences with respect to clone 921F2. Since also at least 40 repetitive units were detected, the size of the $90 \mathrm{E} 5$ allele corresponds to a total array size of 48 repetitive units (Figure 2 ).

A t the 5 ' flanking site two cryptic repeat units were evident $50 \mathrm{bp}$ downstream to the start site of intron 2 (Figure 2). O ne hundred bp downstream to the 5 ' site of intron 2, the following repetitive consensus sequence was found: AGTCT(A/G)GGGCTAGCCCA G TTG GTT. A palindromic sequence able to form a perfect $\mathrm{GC}$-rich 5 base pair hairpin element ( G G G CTA G C C C) is located in the centre of each unit. The fine structure of the cluster revealed variation in the $25 \mathrm{bp}$ unit. A fter 6 conserved repetitive units two of three adjacent cytosin bases are deleted in unit no.7 (Figure 2).

E ven more variation of the consensus sequence was obvious at the $3^{\prime}$ end of the repeat, located $208 \mathrm{bp}$ upstream to the $\mathrm{HindlII}$ site, where the consensus sequence was 'fading out' by two cryptic copies. E very second repetitive copy showed a $24 \%$ variation. It included a deletion of one of the three adjacent cytosine bases. The other copies showed variability within the adjacent three guanosine bases to an overall extent of $8 \%$. These data indicate a high degree of interrepeat variability, which suggests a low frequency of heterozygosity.

\section{A New Single Copy-Minisatellite in the Human Genome}

To determine the abundance of this repeat cluster within the human genome, genomic DNA of three human individuals was digested by $\mathrm{H}$ indllI and subjected to Southern blot analysis using the total array of the repeat cluster ( $1.5 \mathrm{~kb}$ PCR product) as a probe. $B$ eside the $5.8 \mathrm{~kb}$ band no other autoradiographic signal was detected in the genomic DNA as well as in BAC 843E 9 and 921F2 recombinants (data not shown). Sequence data library searching by the 25 bp consensus sequence exhibited no significantly homologous 
sequence. These results indicate that the $25 \mathrm{bp}$ minisatellite is exclusively present in the intron 2 of TFF 2 in human $21 q 22.3$.

\section{A Diallelic Polymorphism in the Caucasian Population}

The genotype distribution and allele frequencies in 78 unrelated white Caucasian subjects is summarised in Table 2. Two alleles were found that are identical in size to those already cloned in $\mathrm{BAC}$ recombinants (Figure 3A). A $120 \mathrm{bp}$ difference in size accounts for the differences of alleles termed ' $A$ ' and ' $a$ ', corresponding to a repeat copy number of 48 and 53 , respectively (Table 2). The allelic distribution agreed well with the $\mathrm{H}$ ardy-Weinberg equilibrium. From size analysis of DNA molecular markers the resolution of gel electro-

Table 2 Genotype and allele frequency in 78 unrelated individuals

\begin{tabular}{llllll}
\hline & A A & A a & aa & A & a \\
\hline $\mathrm{n}=78$ & $56(71.8 \%)$ & $20(25.6 \%)$ & $2(2.6 \%)$ & 0.85 & 0.15 \\
\hline
\end{tabular}

A

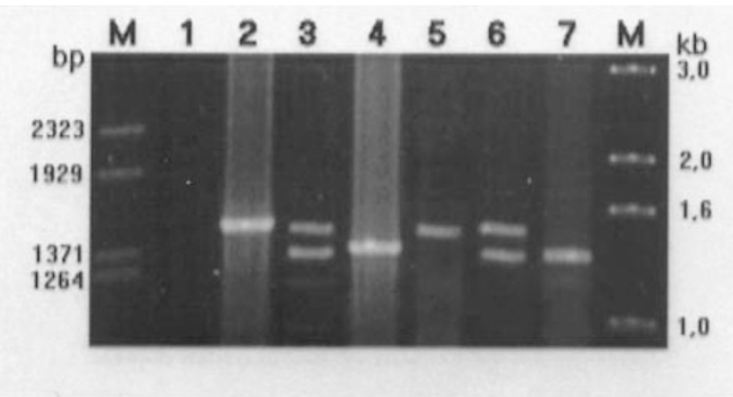

B

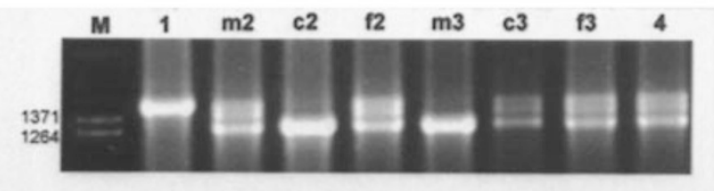

Figure 3 D iallelic polymorphism of the $25 \mathrm{bp}$ repeats shown by PCR amplification with primers SM L F 2 and SIN 2. a) Total array size in BAC recombinants and in unrelated individuals. Slot 1: negative control; 2: BAC 921F 2; 3 and 6: heterozygous individuals; 4: BAC 90E 5; 5: homozygous individual displaying allel ' $a$ '; 7 : homozygous individual displaying allel ' $A$ '; $M$ : DNA size markers. b) Inheritance analysis in two families. Family no. $2(\mathrm{~m} 2, \mathrm{c} 2, \mathrm{f} 2)$ presents a heterozygous mother $(\mathrm{m})$ and father ( $f$ ) and a homozygous child (c), whereas in family no. $3(\mathrm{~m} 3, \mathrm{c} 3, \mathrm{f3})$ only the mother is homozygous. Nos 1 and 4 refer to unrelated homozygous and heterozygous individuals, respectively. The upper band in the heterozygous individuals appeared doubled probably due to a PCR artefact. phoresis used in this study was able to detect a size difference of $25 \mathrm{bp}$, thus excluding the possibility of additional alleles differing in one unit within the panel of 78 unrelated individuals. Inheritance analysis in five families, each including father, mother and one child, showed a Mendelian type of inheritance (Figure 3B). Two families (nos 2 and 3) were genotyped to be heterozygous, the other three were homozygous for the allele A.

\section{Evolutionary Origin of the Repeated Sequence}

The presence of the $25 \mathrm{bp}$ consensus motif was tested in several mammalian species to reveal its evolutionary origin. Classical zooblot analysis was hampered by lack of enough material from some monkey species. U sing $P C R$ with human intron primers flanking the repeats (SMLF2, SIN2), amplified products from chimpanzee (Pan troglodytes) and gorilla (Gorilla gorilla) were probed to be positive for the tandem repeat by Southern hybridisation (Figure $4 a$ and Figure $4 b$ ). In the gorilla, a double band was amplified, indicating heterozygosity in great apes. In other monkeys either no PCR product was found or the hybridisation revealed no signal, presumably because of sequence variation to the human specific intron primers. To circumvent this problem, cross-species primers TFF2E 2F, and TFF2E 3R were designed from conserved human and murine TFF-domain sequences in exon 2 and $3 .^{2}$ Since the exon-intron boundaries are conserved in human and mouse ( $O$ L efebvre, $M-C$ R io, personal communication), the size of the intron can be deduced, and results shown in Figures $4 \mathrm{c}$ and $4 \mathrm{~d}$ are summarised in Table 3. A mplified products were obtained from genomic DNA of mouse $(0.85 \mathrm{~kb})$, rat $(1.0 \mathrm{~kb}), 0$ ryctolagus spec (rabbit; $1.11 \mathrm{~kb}), \mathrm{L}$ emur catta $(1.15 \mathrm{~kb})$, Theropithecus gelada $(1.58 \mathrm{~kb})$, chimpanzee $(2.2 \mathrm{~kb})$ and $\operatorname{man}(2.4 \mathrm{~kb}$ and $2.5 \mathrm{~kb})$, indicating a continuous enlargement of intron 2 during mammalian evolution (Figure 4c, Table 3). When probed for the presence of the tandem repeat, man, chimpanzee and the simian Theropithecus gelada were positive, whereas the lemur species and the other mammalian species were negative (Figure $4 d$, Table 3 ), indicating that the minisatellite was acquired during simian evolution. A dditional bands amplified by the cross-species primer are nonspecific, since they are probed to be negative for the tandem-repeat by hybridisation. D uring the process of reviewing this paper the mouse TFF 2 gene was sequenced ( $G$ enB ank database acc. No. U 78770). Intron 2 has a size of $773 \mathrm{bp}$, which agreed well with the 
A

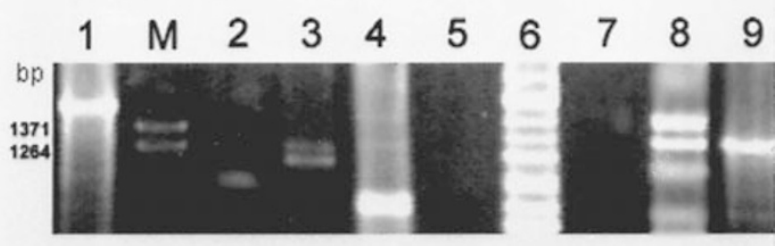

B

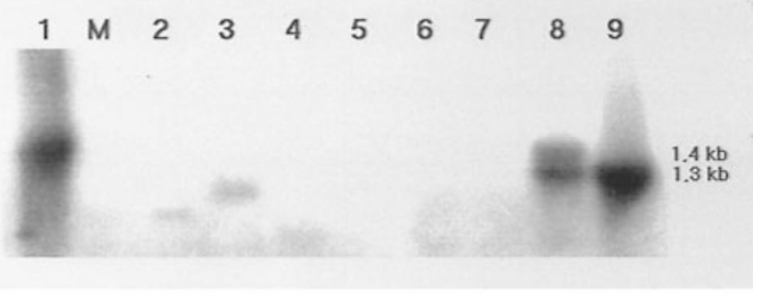

C

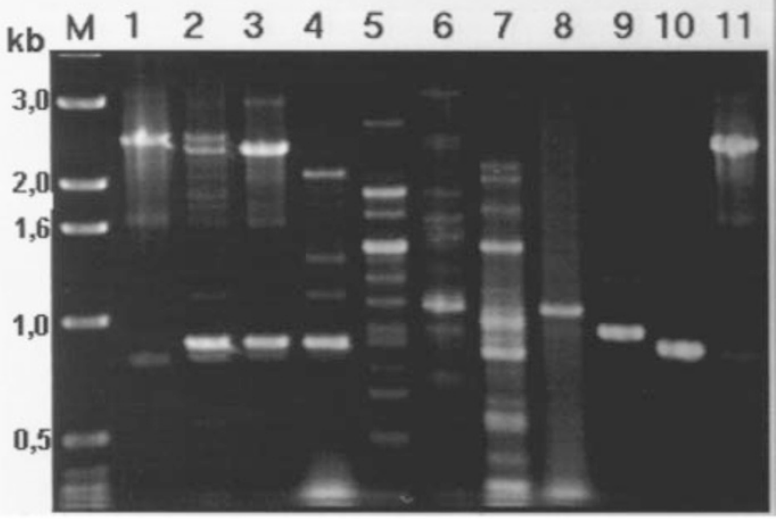

D

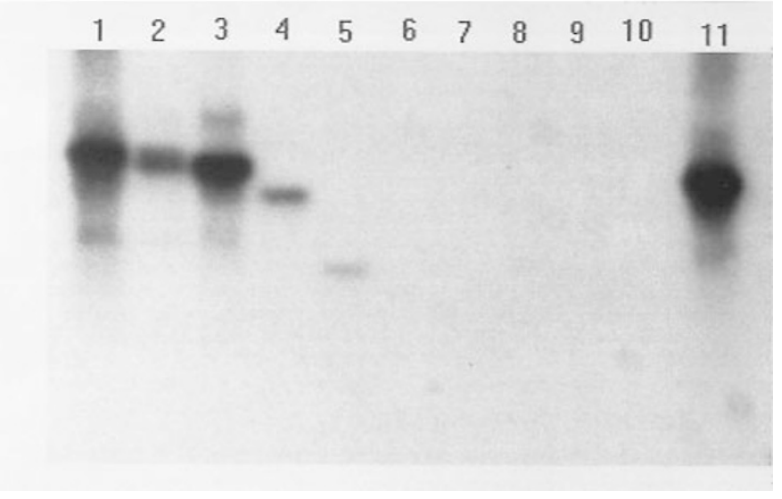

Figure 4 Evolutionary origin of the $25 \mathrm{bp}$ minisatellite. a) PCR amplification with primers SM L F 2 and SI N 2 flanking the minisatellite, using D NA of various sources: 1: BAC 921F 2; 2: Pan troglodytes; 3: G orilla gorilla; 4: Theropithecus gelada (old world monkey); 5: A teles geoffreyi (new world monkey); 6: L emur catta; 7: negative control; 8: heterozygous individual; 9: BAC 90E 5. b) corresponding Southern blot of amplified products hybridised with the 25 bp repeat probe. c) A mplification of the intron 2 of TFF2 in mammalian species by conserved cross-species primers. d) corresponding Southern blot hybridisation with the $25 \mathrm{bp}$ minisatellite probe 1: BAC 921F 2; 2: heterozygous individual; 3: homozygous individual; 4: Pan troglodytes (chimpanzee); 5: Theropithecus gelada; 6 : L emur catta; 7: Sus suis (pig); 8: O ryctolagus spec. (rabbit); 9: R attus norvegicus; 10: M us musculus; 11: BAC $843 E 9$. size of $750 \mathrm{bp}$ determined by our analysis. A Iso, the data from the $G$ enBank database revealed no sequences homologous to the $25 \mathrm{bp}$ tandem repeat.

\section{Discussion}

In the following we describe the characterisation of a minisatellite in intron 2 of TFF 2 coding for the human trefoil factor 2 . Several factors point to the relevance of trefoil peptides in mucosal restitution, eg wound healing and cell motility, differentiation, and association with cancerogenesis. ${ }^{5,10,12,16}$ The application of trefoil peptides as therapeutic agents in several ulcerative diseases has been suggested. ${ }^{9,31}$ Trefoil peptides are coordinately secreted from mucin expressing cells of the normal gastrointestinal tissues and are upregulated in pathological conditions such as damaged epithelia, sites of ulceration, and some meta- and neoplasia. TFF 2 has very restricted expression sites in normal gastrointestinal tissue, since it is limited to the glandular region of the stomach and duodenal Brunner's glands.

The finding of a minisatellite raises at least three possible functional aspects. First, the minisatellite could regulate transcription of TFF2 or the coordinated expression all TFF genes through binding of a transcription factor. Examples are the $14-b p$ repeats $365 \mathrm{bp}$ upstream of the transcription start site of the human insulin gene $\mathrm{e}^{23}$ and the 28 -bp repeats $1 \mathrm{~kb}$ downstream of the polyadenylation site of the human HRAS1 oncogene. ${ }^{32}$ These examples are associated with an increased risk of insulin-dependent diabetes and several cancers, respectively. The palindromic sequence GGGCTAGCCC present in each repeat of the TFF2 intron suggests the existence of a functional DNA

Table 3 O ccurrence of the $25 \mathrm{bp}$ tandem repeat and sizes of intron II in TFF2

\begin{tabular}{llll}
\hline M ammalian & Presence of the & No. of & $\begin{array}{l}\text { Size of } \\
\text { intron }\end{array}$ \\
species & tandem repeata $^{2}$ & 25 bp units $^{a}$ & $2(\mathrm{~kb})^{\mathrm{a}}$ \\
\hline H omo sapiens & +(polymorphic) & $48(\mathrm{~A}) 53(\mathrm{a})$ & $2.3-2.4$ \\
G orilla gorilla & + (polymorphic) & $44 ; 47$ & $\mathrm{n} . \mathrm{d}$. \\
Pan troglodytes & + & 41 & 2.1 \\
Theropithecus & + & $<40$ & 1.5 \\
$\quad$ gelada & - & - & 1.05 \\
L emur catta & - & - & 1.0 \\
Oryctolagus spec. & - & - & 0.9 \\
Rattus norvegicus & - & - & 0.75 \\
M us musculus & - & & \\
\hline
\end{tabular}

aD ata from Figure 4, intron sizes are calculated using the conserved sizes of exons 2 and 3. 
binding protein. The presence of the $25 \mathrm{bp}$ repeats in human and simian primates, but not in lower mammals, would argue for a different regulation of TFF 2 acquired during evolution. In fact. TFF2 is most prominent in porcine pancreas, and is present in mouse and rat acinar cells of the pancreas, whereas it is not found in the human pancreas. ${ }^{2,33} \mathrm{~A}$ lthough no direct relationship of TFF2 with a human disease is yet proven,TFF2 and TFF 1 transcription is coordinately upregulated in some adenomas of stomach, pancreas, and biliary tract. ${ }^{17,18,19}$ On the other hand, TFF1-knockout mice that are also defective in TFF 2 expression develop adenocarcinomas in stomach and duodenum, ${ }^{12}$ which may indicate different regulation in lower mammals.

Secondly, minisatellites can disturb gene expression by instability leading to genomic rearrangements or by expansion processes interfering with transcription on the chromatin level. For example, an expanded 33-bp, A T-rich minisatellite results in the common distamycin A-sensitive fragile site, FRA 16B causing fragile $X$ syndrome. ${ }^{26}$ The small alleles containing 7-12 sequenceheterogeneous repeats are enlarged up to 2000 copies of one repeat type in F RA 16B. Thirdly, recent examples show that minisatellite expansion disrupt gene expression by yet unknown mechanism. The expansion of a G C-rich 12-bp repeat unit is responsible for a monogenic form of epilepsy termed EPM 1.25,34 This repeat, normally present in 2-3 copies in normal alleles of the promoter region of the gene encoding cystatin $B$ is expanded to a large insertion (600-900 bp) leading to inhibition of transcription in affected patients.

The use of the $25 \mathrm{bp}$ minisatellite in TFF 2 for $\mathrm{LOH}$ studies is somewhat hampered by the low frequency of heterozygosity (26\%). However, it may be of great interest to study the stability of this repeat cluster, especially in clinical collectives displaying chronic gastritis, gastric dys- and neoplasia, or inflammatory bowel disease (Crohn's disease, ulcerative colitis), conditions that are likely to be linked to TFF expression. Two commonly deleted regions on $21 q$ in differentiated gastric adenocarcinomas have been recently suggested. ${ }^{35}$ Studies to determine the role of this repeat in transcriptional regulation and in gastric carcinogenesis are currently being undertaken.

\section{Acknowledgements}

We would like to thank J Kömpf, C Luckenbach and R Pöltl for providing human and mammalian DNA samples. We are indebted to $\mathrm{N}$ Blin for helpful discussions. The study was supported by a grant from the Deutsche Krebshilfe
(10-1120-Gö1) and the BMBF (01K S9602). S Beck is a recipient of a Baden-W ürttemberg predoctoral training grant.

\section{References}

1 Thim L: A new family of growth factor-like peptides. 'Trefoil' disulphide loop structures as a common feature in breast cancer associated peptide (pS2), pancreatic spasmolytic polypeptide (PSP), and frog skin peptides (spasmolysins). FE BS L ett 1989; 250: 85-90.

2 Tomasetto C, R io MC, G autier $C$ et al: hSP, the domainduplicated homolog of pS2 protein, is co-expressed with pS2 in stomach but not in breast carcinoma. EMBO J 1990; 9: 407-414.

3 H offmann W, H auser F: The P-domain or trefoil motif: a role in renewal and pathology of mucous epithelia? Trends Biochem Sci 1993; 18: 239-243.

4 Sands BE, Podolsky D K : The trefoil peptide family. A nnu Rev Physiol 1996; 58: 253-273.

5 W right NA, H offmann W, O tto WR, R io M-C, Thim L: Rolling in the clover: Trefoil factor family (TFF) domain peptides, cell migration and cancer. FE BS L ett 1997; 408: 121-123.

6 Dignass A, Lynch Devaney $K$, Kindon $H$, Thim L, Podolsky DK: Trefoil peptides promote epithelial migration through a transforming growth factor beta-independent pathway. J Clin Invest 1994; 94: 376-383.

$7 \mathrm{~K}$ indon $\mathrm{H}$, Pothoulakis $\mathrm{C}$, Thim $\mathrm{L}$, Lynch Devaney $\mathrm{K}$, Podolsky DK: Trefoil peptide protection of intestinal epithelial barrier function: cooperative interaction with mucin glycoprotein. Gastroenterology 1995; 109: 516-523.

8 A lison M R, Chinery R, Poulsom R, A shwood P, L ongcroft $J M$, W right NA : Experimental ulceration leads to sequential expression of spasmolytic polypeptide, intestinal trefoil factor, epidermal growth factor and transforming growth factor alpha mR NA s in rat stomach. J Pathol 1995 175: 405-414.

9 Babyatsky M W, D eB eaumont M, Thim L, Podolsky DK: Oral trefoil peptides protect against ethanol- and indomethacin-induced gastric injury in rats. Gastroenterology 1996; 110: 489-497.

10 Playford RJ, Marchbank T, Chinery R et al: Human spasmolytic polypeptide is a cytoprotective agent that stimulates cell migration. Gastroenterology 1995; 108: 108-116.

11 Mashimo $\mathrm{H}$, Wu DC, Podolsky DK, Fishman MC: Impaired defense of intestinal mucosa in mice lacking intestinal trefoil factor. Science; 1996; 274: 262-265.

12 L efebvre 0, Chenard M P, M asson R et al: G astric mucosa abnormalities and tumorigenesis in mice lacking the pS2 trefoil protein. Science 1996; 274: 259-262.

13 Schmitt $\mathrm{H}$, Wundrack I, Beck S et al: A third P-domain peptide gene, human intestinal trefoil factor (TFF3), maps to 21q22.3. Cytogenet Cell G enet 1996; 72: 299-302.

14 Theisinger B, Welter C, Grzeschik KH, Blin N: A ssignment of the gene for human spasmolytic protein (hSP/ SML 1) to chromosome 21. Hum Genet 1992; 89: 681-682. 
15 Beck S, Schmitt H, Shizuya H, Blin N, G ött P: Cloning of contiguous fragments from human chromosome 21 harbouring three trefoil peptide genes. H um G enet 1996; 98 : 233-235.

16 G ött P, B eck S, M achado J C, Carneiro F, Schmitt H, Blin $\mathrm{N}$ : H uman trefoil peptides: G enomic structure in 21q22.3 and coordinated expression. E ur J Hum G enet 1996; 4: 308-315.

17 Theisinger B, Welter C, Seitz G, Rio MC, L athe R, Chambon $\mathrm{P}$, Blin $\mathrm{N}$ : Expression of the breast cancer associated gene pS2 and the pancreatic spasmolytic polypeptide gene (hSP) in diffuse type of stomach carcinoma. E ur J Cancer 1991; 27: 770-773.

18 Welter C, Theisinger B, Seitz G, Tomasetto C, R io M C, Chambon $\mathrm{P}$, B lin N : A ssociation of the human spasmolytic polypeptide and an estrogen-induced breast cancer protein (pS2) with human pancreatic carcinoma. L ab Invest 1992; 66: 187-192.

19 Seitz G, Thelsinger B, Tomasetto G, R io M C, Chambon P, Blin N, Welter $G$ : B reast cancer-associated protein $\mathrm{pS2}$ expression in tumors of the biliary tract. A m J Gastroenterol 1991; 86: 1491-1494.

20 W right NA, Poulsom R, Stamp G et al: Trefoil peptide gene expression in gastrointestinal epithelial cells in inflammatory bowel disease. G astroenterology 1993; 104: 12-20.

21 Jeltsch J M, R oberts M, Schatz C, G arnier J M , B rown A M, Chambon P: Structure of the human oestrogen-responsive gene pS2. Nucleic A cids Res 1987; 15: 1401-1414.

22 Seib T, Dooley S, Welter C: Characterization of the genomic structure and the promoter region of the human intestinal trefoil factor. Biochem Biophys Res Commun 1995; 214: 195-199.

23 K ennedy G C, G erman M S, R utter WJ : The minisatellite in the diabetes susceptibility locus ID D M 2 regulates insulin transcription. Nature G enet 1995; 9: 293-298.

.24 Virtaneva K, D'A mato $E$, Miao IM et al: Unstable minisatellite expansion causing recessively inherited myoclonus epilepsy, E PM 1. Nature G enet 1997; 15: 393-396.
25 Lalioti MD, Scott HS, Buresi $C$ et al: Dodecamer repeat expansion in cystatin $B$ gene in progressive myoclonus epilepsy. N ature 1997; 386: 847-851.

26 Y u S, M angelsdorf M, H ewett D et al: Human chromosomal fragile site FRA 16B is an amplified AT-rich minisatellite repeat. Cell1997; 88: 367-374.

27 Shizuya $H$, Birren B, Kim UJ, Mancino V, Slepak T, Tachiiri $Y$, Simon $M$ : Cloning and stable maintenance of 300-kilobase-pair fragments of human DNA in Escherichia coli using an F-factor-based vector. Proc $\mathrm{N}$ atl A cad Sci USA 1992; 89: 8794-8797.

28 Chomczynski P: O ne-hour downward alkaline capillary transfer for blotting of DNA and RNA. A nalytical Biochemistry 1992; 201: 134-139.

$29 \mathrm{~K}$ ang HK, Cox DW: Tandem repeats 3 ' of the IG H A genes in the human immunoglobulin heavy chain gene cluster. Genomics 1996 35: 189-195.

30 Seib T, Blin N, Hilgert $\mathrm{K}$ et al: The three human trefoil genes TFF 1,TFF 2 and TFF 3 are located within a region of $55 \mathrm{~kb}$ on chromosome 21q22.3. Genomics 1997; 40: 200-202.

31 Featherstone C: Soothing the troubled gut with trefoil factors. $L$ ancet 1997; 349: 706.

32 Green M, K rontiris T G : A llelic variation of reporter gene activation by the HRA S1 minisatellite. G enomics 199317 : 429-434.

33 Taupin D R, Pang K C, Green SP, G iraud A S: The trefoil peptides spasmolyitc polypeptide and intestinal trefoil factor are major secretory product of the rat gut. Peptides 1995; 16: 1001-1005.

34 Lafrenière R G, R ochefort $D L, C$ hrétien $N$ et al: $U$ nstable insertion in the $5^{\prime}$ flanking region of the cystatin $B$ gene is the most common mutation in progressive myoclonus epilepsy type 1, E PM 1. Nature G enet 1997; 15: 298-302.

35 Sakata K, Tamura G, N ishizuka S et al: Commonly deleted regions on the long arm of chromosome 21 in differentiated adenocarcinoma of the stomach. G enes, chromosomes \& cancer 1997; 18: 318-321. 